
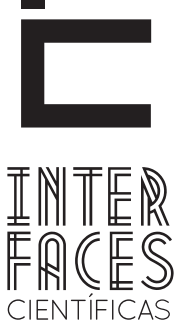

SAÚDE E AMBIENTE

ISSN IMPRESSO 2316-3313

\title{
A NARRATIVA QUE DESVELA OS CONFLITOS SOCIOAMBIENTAIS NO BRASIL ${ }^{1}$ THE NARRATIVE THAT UNVELLS THE SOCIO ENVIRONMENTAL CONFLICTS IN BRAZIL LA NARRATIVA QUE DESVELA LOS CONFLICTOS SOCIOAMBIENTALES EN BRASIL
}

Edvan Lessa ${ }^{1}$

\section{RESUMO}

Afirmar que há uma narrativa sobre conflitos socioambientais envolve identificar um esforço sistemático de divulgação de informações sobre essas situações nas quais há disputas, entre diferentes sujeitos, a partir dos usos de recursos do meio ambiente. Nosso argumento neste artigo é de que a Comissão Pastoral da Terra (CPT), ação pastoral da igreja católica, e a Fundação Instituto Oswaldo Cruz (FIOCRUZ), instituição pública vinculada ao Ministério da Saúde, elaboram esta narrativa formada por argumentos escritos, lançada à apreciação pública e que serve como instrumento de denúncia. A narrativa aparece no cruzamento fei-

1. Artigo baseado na dissertação de Mestrado “Água Mole, Terra Dura, Povo Brada Até que Fura ( 0 que narram CPT e Fiocruz sobre os conflitos socio-
Antonio Carlos Rodrigues de Amorim²

to entre 14 relatórios Conflitos no Campo Brasil, veiculados pela CPT anualmente desde 1985 e Mapa de Conflitos, envolvendo Injustiça Ambiental e Saúde no Brasil, lançada em 2010 pela Fiocruz e atualizado periodicamente. Ambos são produtos distintos e há conexão entre eles, sendo os principais resultados deste trabalho a constatação da existência de uma narrativa comum e articulada que evidencia o conflito ambiental em um contexto de catástrofe e de seus riscos e formas de contenção, via percepção de seus sentidos complexos que emergem a partir do trabalho analítico com marcadores discursivos específicos.

ambientais no Brasil)", defendida no dia 29 de agosto de 2017 no Labjor/ Unicamp. Financiamento: CNPq 


\section{PALAVRAS-CHAVE}

Conflitos Socioambientais. CPT. Fiocruz. Narrativa Científica.

\section{ABSTRACT}

To affirm that there is a narrative about socio-environmental conflicts involves identifying a systematic effort of information dissemination about these situations in which there are disputes, between different agents, based on the uses of environmental resources. Our argument in this study is that the Pastoral Land Commission (CPT), pastoral action of the Catholic Church, and the Oswaldo Cruz Institute Foundation (Fiocruz), a public institution linked to the Ministry of Health, elaborate this narrative formed by written topics, which are released to public appreciation and serves as an instrument of denouncement. The narrative appears at the intersection between 14 reports called Field Conflicts in Brazil, published annually by CPT since 1985, and Map of Conflicts involving Environmental Injustice and Health in Brazil, released in 2010 by Fiocruz and updated periodically. Both are distinct products and there is a connection between them, which is the main result of this work: the existence of a common and articulated narrative that shows the environmental conflict in a context of catastrophe and its risks and forms of containment, through the perception of their complex senses that emerge from analytical work with specific discursive markers.

\section{KEYWORDS}

Social Environmental Conflicts. CPT. Fiocruz. Scientific Narrative.

\section{RESUMEN}

Afirmar que hay una narrativa sobre conflictos socioambientales significa identificar un esfuerzo importante de divulgación de información sobre las situaciones con disputas, entre diferentes sujetos, a partir de los recursos humanos de medio ambiente. Nuestro argumento en este artículo, es que la Comisión Pastoral de la Tierra (CPT), una acción pastoral de la iglesia católica, y la Fundação Instituto Oswaldo Cruz (Fiocruz), organización pública vinculada al Ministerio de la Salud Pública, sirve como instrumento de denuncia. La narrativa nació después de investigar 14 informes de conflictos en el campo brasileño, pu- blicados por la CPT a cada año desde 1985. También fueran estudiados los datos del mapa de conflictos que involucran Injusticia Ambiental y Salud en Brasil, lanzado en 2010 por Fiocruz y actualizado periódicamente. Los dos son productos distintos y están conectados. El principal resultados de este trabajo es la constatación de la existencia de una narrativa común y articulada que evidencia o conflicto ambiental en un contexto de catástrofe y de sus riesgos y formas de contención, a través de la percepción de sus sentidos complejos que emergen desde el trabajo analítico con marcadores discursivos específicos. 


\section{PALABRAS CLAVE}

Conflictos socioambientales, CPT, Fiocruz, Narrativa científica.

\section{INTRODUÇÃO}

O conflito em sociedade pode indicar que algo no contexto das relações grupais/interpessoais precisa de mudança. Daí que alguns autores das ciências sociais vão falar em potencial criativo dos conflitos. A Comissão Pastoral da Terra (ACPT) e a Fundação Instituto Oswaldo Cruz (FIOCRUZ), consideram os aspectos mais controversos dos conflitos, não os aceitando como ocorrências naturais e, sim, fruto de tensões arbitrárias, muitas vezes evitáveis.

Por meio dos mapeamentos realizados por Fiocruz e CPT, os conflitos socioambientais são retratados do ponto de vista de suas consequências nocivas para povos do campo e, em menor grau, pessoas em zonas urbanas. Muitas vezes porque projetos de desenvolvimento econômico ou políticas públicas salientam as diferentes visões de sujeitos em relação à apropriação de bens naturais.

Posto isso, e diante também da importância das lutas serem trazidas a público, neste artigo nos dedicaremos a notar como a Pastoral (CPT) e a Fiocruz organizam uma narrativa a partir de livros impressos e mapa on-line. Detalharemos a forma desta narrativa, separando os seus argumentos em "etiquetas" chamadas de "situacionalidade", "representatividade", "vulnerabilidade", "cientificidade", "religiosidade" e "papel da imprensa", as quais nos indicam a existência de uma história sobre as lutas por recursos naturais.

Essas etiquetas nos mostram que saberes canônicos, notadamente religião e ciência, operariam para legitimar a narrativa e, obviamente, a luta das populações, quase sempre invisibilizada pela imprensa. Os meios de comunicação, nesse contexto, atuariam como antagonistas de interesses democráticos de po- vos e comunidades tradicionais e, ao mesmo tempo, fonte destacada por vez ou outra, repercutir casos de conflito, tal como caderno e mapa.

Nessa história, a crise da água, por exemplo, inflamaria os casos, e as estatísticas robustas seria o modo de apresentar e dimensionar os casos. Entretanto, os números rigorosamente coletados e interpretados por especialistas são, como se constatará, questionados pelas próprias instituições que os fabricam: mostram e/ou ocultam os rostos das populações envolvidas nos conflitos?

Para realizar este trabalho, analisamos 14 edições dos relatórios Conflitos no Campo Brasil, da CPT, e do Mapa de Conflitos da Fiocruz, percorrendo páginas impressas e virtuais, tentando etiquetar a narrativa e, identificando aspectos implícitos e explícitos nos textos que divulgam os conflitos por recursos hídricos e tentando especular o que essa narrativa produziria.

\section{ENTENDENDO OS CONFLITOS}

Conflito é um termo transitivo. E por sua transitividade depende de complementos explicativos: contexto, personagens, antecedentes e ambientação. 0 conflito na sociedade é, obviamente, um conflito social. Pode existir em escalas maiores ou menores - embora sejam plausíveis independentemente da quantidade de atores envolvidos - e diante de determinados antagonismos esperados, até mesmo nos núcleos supostamente mais homogêneos.

Conforme Galtung (1996), cada conflito pressupõe uma contradição, algo que está no caminho de algo 
mais, o que para ele é um problema. E é justamente um problema a ser resolvido que, segundo o autor, poderia servir como força motora para atores individuais ou coletivos (GALTUNG, 1996, p. 70). Outros teóricos discordam especialmente da ideia de "problema" vinculada a esta afirmação.

A autora Lúcia Ferreira (2005, p.105) problematiza que talvez por estarem na constituição de problemas ambientais, "conflito" e "problema" foram confundidos como sinônimos. Para nós, apoiados em Valencio e Zhouri (2013), o conflito, envolvendo recursos naturais tem como ponto de partida o processo social e a existência de relações entre sujeitos sociais indissociados do meio em que habitam. Por isso, compreende-se a importância atribuída a todo constrangimento que infrinja ou crie mazelas para as pessoas em/e ambientes constitutivos de seus modos de vida.

A ideia de conflito, envolvendo recursos naturais viria, entretanto, borrar a aparente objetividade das noções de problema e de impacto. O que implica, segundo Valencio e Zhouri (2013), no questionamento baseado da noção de meio ambiente como realidade objetiva e externa à sociedade e, portanto, passível de apreensão e mensuração técnica e científica.

Derivadas das afirmações acima, podemos provocar: problemas ambientais poderiam converter-se em conflitos? Ou a existência de um problema, justamente em decorrência de algum conflito implicaria nesta noção de "problema" da qual autores mencionados aproximam-se ou tentam afastar-se? Ainda que não ocorra de forma imediata, o conflito se dá quando os atores sociais afetados percebem suas perdas e entram em disputa. Mas nem todo problema ambiental decorreria de um conflito (BRASIL, 2015).

Conforme propõe a CPT, por definição, conflitos são

As ações de resistência e enfrentamento que acontecem em diferentes contextos sociais no âmbito rural, envolvendo a luta pela terra, água, direitos e pelos meios de trabalho ou produção. Estes conflitos acontecem entre classes sociais, entre os trabalhadores ou por causa da ausência ou má gestão de políticas públicas. (CANUTO; LUZ; ANDRADE, 2016).
São conflitos no âmbito rural, por isso são chamados de conflitos no campo, embora não assumam faces tão distintas assim daqueles ocorridos em meio urbano.

No caso da Fiocruz, estudamos a edição de seu livro "Injustiça Ambiental e Saúde no Brasil: O Mapa de Conflitos" para realçar como estão articulados os conceitos de conflitos sob os quais se organizam os casos do Mapa de Conflitos, disponível na internet. 0 conflito, para a Fiocruz, está relacionado ao conceito de justiça. Injustiça e discriminação estariam, então, entre as causas primeiras dessas disputas. Com base em Funtowicz e Ravetz (1994 apud LEROY; PORTO; PACHECO, 2013), conflitos, além de valores e incertezas, caracterizam os problemas socioambientais mais graves e urgentes da nossa época.

Para a justiça ambiental, nos indica a Fiocruz, reconhecer somente dificuldades e injustiças enfrentadas pelas populações atingidas pelos conflitos não é o bastante. Faz-se necessário transformá-las em questões concretas, motivos de ação e transformação conscientes e organizados por parte, tanto das populações afetadas, quanto da sociedade em geral. Somente deste modo haveria política para enfrentar os problemas, isto é, à medida que problemas sejam explicitados e reconhecidos como embates ou conflitos que refletem os diferentes interesses, visões de mundo e projetos de desenvolvimento em disputa (LEROY; PORTO; PACHECO, 2013, p. 16).

\section{A NARRATIVA QUE DIVULGA OS CONFLITOS}

Os relatórios da Comissão Pastoral da Terra e o Mapa da Fundação Oswaldo Cruz possuem aproximações textuais, semânticas, subjetivas e culturais, não apenas por caracterizarem os conflitos, guiando-se por entendimentos teóricos. É importante que se frise: a definição acima nos orienta sobre o que também entendemos por conflitos. Nesta publicação não verificamos como os conceitos trazidos por Fiocruz e CPT têm aproximações ou distinções dos pensamentos de outros autores. 
Cruzamos as duas publicações e delas extraímos fragmentos de textos, embora não reproduzidos aqui, que, ora utilizamos nas nossas argumentações e contextualizações, ora analisamos como objeto propriamente, na busca por mais ou menos denotar a existência de uma narrativa baseada na ciência. A contribuição deste trabalho opera no sentido de buscar verificar quais semânticas operariam nas publicações sobre conflitos e como a constante coleta e divulgação de dados que contribui para manter na agenda pública, talvez não no âmbito desejado - o de tomada de decisão política, no final das contas se vale de um procedimento metodológico padrão para acomodar uma diversidade de "atingidos".

Nosso argumento é que a narrativa sobre a existência dos conflitos socioambientais/pela água se consolida de forma similar com a empenhada por pesquisadores ao tornar conhecido o problema da chuva ácida e do aquecimento global, como veremos adiante. Na leitura dos textos que contextualizam os dados publicados, vemos alguns elementos constantemente presentes, o que faz com que insistamos na ideia de uma narrativa.

Os elementos que formam a narrativa científica e política dos conflitos dizem respeito à escolha semântica para divulgar e/ou informar as disputas reconhecidas e validadas por essas instituições, seja por meio de justificativas baseadas em ciência (cientificidade), seja pela metodologia e a versão final de como essas informações são divulgadas (e padronização e sistematização de dados).

Os marcadores ou etiquetas, entre eles o que demarca a dimensão científica das publicações, dão tônica à narrativa principal, percebida nas leituras continuadas dos arquivos/publicações da CPT e Fiocruz. Não eram marcadores/etiquetas prontas, já dadas. Seus nomes, suas características e "simetrias" foram construídas por meio de um trabalho sistemático de inventariar falas recorrentes e perceber o não dito nessa narrativa.

A narrativa contém a história sobre embates vinculados a demandas ambientais reais. Uma história mediada por diferentes sujeitos (aqueles que coletam as evidências, aqueles que as organizam e os que irão interpretar os dados em ensaios e artigos). E, ao menos nos fragmentos lidos, praticamente nenhuma presença expressiva de quem estaria assujeitado às mazelas mostradas em dados.

0 que estamos chamando de narrativa é um maciço textual - ampliado por ações outras desenvolvidas pelas instituições autoras - com uma pauta muito bem delimitada: os conflitos socioambientais nas zonas: rural e urbana do País. Nosso olhar é que prioriza aqueles que acontecem por causa da água, que foi ou pode ser comprometida. Nos textos lidos, predominantemente os da CPT, até pela experiência no assunto, essa era a pauta buscada e o que fez com que não tivéssemos que rastrear a média de 200 páginas por edição, de 2003a 2016 (CANUTO; LUZ, 2003; AFONSO; CANUTO; LUZ; 2004; CANUTO; LUZ; 2005, 2006; CANUTO et al., 2007, 2008, 2009, 2010; CANUTO; LUZ; WICHINIESKI, 2011, 2012; CANUTO; LAZZARIN; LUZ; 2013, 2014; CANUTO; COSTA, LUZ; 2015; CANUTO; LUZ; ANDRADE, 2016).

Percebemos, então, somando-se os elementos narrativos, mais à frente listados, que a história contada no Mapa e Cadernos é montada em camadas. É bom que se frise: são publicações individuais, cada uma desvelando casos de um jeito particular. Isso nos levaria a pensar que não existe, então, uma narrativa sobre conflitos, mas "narrativas". Quando falamos em maciço textual, todavia, não desprezamos as tais camadas que, ao serem sedimentadas, formam a narrativa.

\section{CARACTERÍSTICAS geraIS DA NARRATIVA CIENTÍFICA}

A noção de "narrativa" em que inicialmente nos apoiamos foi percebida no capítulo "Cientistas e Agenda Setting" da obra Ciência e Política Ambiental, cuja autoria é de Ann Campbell Keller (2009). No livro, Keller descreve o assunto a partir da percepção de narrativas científicas as quais tornaram públicos 
os fenômenos da chuva ácida e do aquecimento global, e a maneira que essas histórias contribuíram para que os respectivos problemas ambientais ocupassem a agenda política formal nos países em que tiveram repercussão inicialmente.

No final das contas, a CPT e a Fiocruz teriam como intenção que, além de conhecidos, os conflitos possam ser entendidos não como fenômenos constitutivos da sociedade, mas como ocorrências forçadas por distorções político-econômicas e culturais. Principalmente se considerarmos os entendimentos naturalizados por empresas e até tomadores de decisão política acerca do modelo de desenvolvimento atroz em vigência e estruturante das nossas vidas.

Posto isso, Keller nos avisa que a narrativa científica é assim chamada por fazer, obviamente, endosso da ciência. Em nossa visão, dando a entender que as situações narradas - no caso, os conflitos socioambientais protagonizados principalmente por populações rurais - precisam de sustentáculo, pois de outro modo seriam preteridas, descaracterizadas, desacreditadas ou ocultadas.

A ciência aparece na função de explicar o problema; uma característica comum às narrativas do aquecimento global e chuva ácida; ou seja, na enunciação de um desastre ou de um desequilíbrio ambiental. Isso já nos dá pistas de que noções de ciência circundantes nessas histórias estão fortemente repousadas nos ideais positivistas, respaldadas na objetividade, na experimentação e na generalização da análise de dados extraídos de realidades específicas para divulgar um tema de notável alcance social e ambiental.

Um tipo específico de narrativa científica, então, é conduzido por cientistas/pesquisadores que fornecem um mapa conceitual sobre determinado tema, o qual inicialmente estará alheio ou totalmente isolado do mundo político. No caso da narrativa constituída sobre os conflitos, na verdade, os argumentos políticos estão bem denotados e repetidos já na elaboração da história que se conta acerca das disputas pela água. Algo percebido, aliás, não apenas quando tomamos contato com os objetivos das publicações da CPT e Fiocruz, mas também quando somos introduzidos ao conteúdo que contextualiza os dados coletados e que compõem as estatísticas.

A autoria da narrativa científica e política, acerca de disputas ambientais, também inclui sujeitos atuantes em outros âmbitos, não apenas nas instituições acadêmicas. A dose de religião existente na narrativa indica que os conflitos socioambientais só podem ser lançados a conhecimento público se antes forem digeridos e embalados de saberes canônicos (ciência e religião), os quais os despem de invalidações arbitrárias.

Com base na leitura de Keller, os cientistas antecipam e reagem aos atores não cientistas, conferindo ou indeferindo o estatuto de ciência circulante na narrativa. Aqui cabe dizer que Keller observou a composição de uma narrativa em eventos científicos, reportagens em jornais, além de resultados em relatórios, dentre outros. Nesta pesquisa, consideramos somente a narrativa composta em um âmbito muito específico: o das publicações da Fiocruz e CPT sobre os conflitos socioambientais. São textos, números, dentre outros documentos/arquivos publicados e acessíveis ao público, seja em meio impresso ou e/ou online.

Ainda que obtenha o status de "científica", a narrativa baseada na ciência, conforme já sugerimos, pode não ser um produto objetivo de investigação de cientistas e pesquisadores ou pode ainda não montar um mosaico estritamente baseado em certezas ditas científicas. Nos casos observados por Keller, os argumentos causais sobre aquecimento global e chuva ácida foram cientificamente elaborados e postos dentro de uma história ampliada de declínio e controle. Semelhante aos cientistas divulgadores do aquecimento global e da chuva ácida, os atores da CPT e Fiocruz se tornaram porta-vozes legítimos dos conflitos socioambientais ocorridos no Brasil, argumentando também que esses representam uma questão política relevante.

Incerteza e potencial de danos são dois pontos importantes dessa narrativa que chama a atenção para perguntas das quais cientistas e políticos são convocados a responder. No caso da narrativa sobre os conflitos, os cientistas que não assumem a autoria da narrativa necessariamente convocam os tomadores de decisão a responder. 
Apesar de com forte dose de elementos científicos, há comentários políticos, religiosos e culturais na narrativa, não havendo evidência empírica para compor todos os argumentos causais. É como se o próprio Mapa e os Cadernos fossem a tal evidência e por isso se estruturaria baseada na ciência para obter essa conformidade que geralmente é prezada no âmbito político que costuma inviabilizar os conflitos em menor escala, sobre os quais Fiocruz e CPT mais falam.

A narrativa científica, por esses motivos, deve ser observada com ressalva e sem o status de objetividade recorrentemente atribuído ao meio científico. Não existe uma única natureza dos eventos agrupados em um contexto significativo e que compõem a história. Keller nos disse que uma narrativa desse tipo pode estabelecer um acontecimento como problema político, alocar a culpa e pontuar possíveis soluções. Por pressupor uma resposta política, continua a autora, requer elementos prescritivos e não apenas descritivos.

Ademais, essas narrativas fornecem contexto (etiqueta situacionalidade) para um determinado problema e funcionam como veículo para encaminhar reivindicações científicas até a arena política, sem necessariamente uma explicação ou fundamentação robusta. As descobertas, nos alerta Keller, são muitas vezes imprecisas.

A autora nos avisa que narrativas baseadas na ciência fornecem explicações causais e relatam de que maneira se devem julgar os eventos ligados ao problema em questão. Apesar da ciência não ser o campo mais comum para a contação de histórias, há uma confiança atribuída à informação científica. Os fenômenos são frequentemente apresentados como se fossem inteiramente factuais, repousando sobre a autoridade da ciência. No caso dos conflitos, ainda estão amparados por discursos religiosos, sobretudo cristãos.

A narrativa baseada na ciência e política constituída pelos Cadernos e Mapa possui elementos que tornam ainda mais complexas as características iniciais apresentadas por Ann Keller.

\section{PERCURSO ANALÍTICO}

Fizemos a sistematização das informações obtidas dos materiais por meio de tabelas, considerando cada edição lançada por CPT, desde 2002, e a única edição em livro do Mapa de Conflitos (LEROY; PORTO; PACHECO, 2013), que conta também com uma plataforma on-line (LEROY; PORTO; PACHECO, 2010), em que nos valemos de textos complementares. À esquerda da referida tabela organizamos o nome da etiqueta previamente idealizado (algumas foram dispensadas, então pode haver outras não listadas) e, à direita, trechos que reproduzimos para embasar nossa percepção de como a narrativa é categórica, não linear e, ao mesmo tempo, ambígua.

É ambígua por ser uma história com personagens, mas ao mesmo tempo sem eles; por ter forte relação com a imprensa/meios de comunicação no sentido do que produzem como evidência a favor ou em desfavor da "causa" da Pastoral e Fiocruz. Pouca luz é lançada sobre as histórias de vida e sobre outras demandas das populações (etiqueta papel da imprensa).

Concentramo-nos em textos de "Apresentação", "Metodologia", "Seção Conflitos pela água/Conflitos em tempos de seca", "Notas emitidas pela pastoral" e também em excertos avulsos que contextualizavam a situação dos conflitos no Brasil, em 14 relatórios Conflitos no Campo Brasil. No caso da Fiocruz, somando-se as informações do mapa efetivamente, junto com os textos de apoio on-line e do livro que explica a ferramenta, identificamos alguns cruzamentos com 0 material da CPT.

As etiquetas narrativas foram percebidas no "Prefácio", "Apresentação", "Metodologia" e textos avulsos do livro: Injustiça Ambiental e Saúde no Brasil: O mapa de conflitos, assim como em fragmentos publicados no site em que o mapa pode ser acessado. Conforme notamos, quantitativamente existem pelo menos oito itens que compõem a narrativa sobre conflitos da CPT e Fiocruz.

No caso da primeira, percebemos a existência de etiquetas/marcadores sobre a "situacionalidade dos 
conflitos”, referentes também à "representatividade dos dados divulgados"; "compromisso com os mais vulneráveis"; "noções de ciência”, "citações/considerações sobre religião" e posições definidas sobre os "papéis da imprensa/dos meios de comunicação". Além desses, a Fiocruz destaca "aspectos políticos" e uma "visão ampliada de saúde" imanente aos conflitos.

As etiquetas ou os elementos narrativos, como se vê, estão em sua maioria presentes nas duas "histórias”. Outras foram mais específicas da CPT ou Fiocruz, entretanto, complementam-se. É provável que se questione a expressividade dessas etiquetas narrativas e até que ponto elas sustentam-se. Bom, elas nos servem para entender mais a fundo como a narrativa principal é montada e, mesmo que haja desacordo em relação aos nomes escolhidos, eles são fruto de trabalho interpretativo - rigoroso na busca pela sustentação, mas que pode também ser lido de outras formas.

As "noções de ciência” presentes tanto nas definições descritas, quanto na forma final adquirida e assumida pelas publicações da Fiocruz e CPT nos levam a notar que a ciência é, talvez, um tipo de embalagem e ainda regula os documentos. É de fato o que endossa os argumentos e explica muito sobre como as informações são organizadas, metodologicamente falando. Ao analisar este componente da narrativa, vemos uma posição sempre privilegiada, ainda que problematizada, do âmbito científico.

As posições definidas sobre os papéis da imprensa e dos meios de comunicação, apontados como fonte e como contraponto, se justificariam no argumento de que muitas vezes jornais descaracterizam os atores dos conflitos, ao mesmo tempo em que são responsáveis por tornarem diversas situações públicas, antes de qualquer sistematização robusta ou documental, como é feito nos relatórios e mapa.

A situacionalidade dos conflitos é outro traço característico da narrativa sobre conflitos, encontrado tanto nos cadernos, quanto no mapa. Nesse aspecto, pode haver a intenção de adequar os casos relatados ao contexto ampliado, constituindo uma visão sistêmica que recupera o passado, atualiza a narrativa e faz projeções para o futuro. "Como um rio que tem um longo percurso até o mar, muita água vai mover os moinhos dos conflitos. Infelizmente" (MALVEZZI, 2008 apud CANUTO et al., 2008).

Os mapas, tabelas e outros formatos que caracterizam as publicações sobre conflitos estão entre as escolhas de sistematização das informações, sobretudo os números. No entanto, comumente é questionada a sua potência de acomodar as diversidades e complexidades inerentes aos sujeitos envolvidos nos conflitos e suas demandas. Os dados são significativos, evidenciam o esforço contínuo de divulgar os conflitos e a persistência deleds, mas até que ponto eles mostram efetivamente o traço distintivo das pessoas que vivem em áreas onde se diz que há conflitos?

Outro quesito importante quando a CPT e Fiocruz apontam para os conflitos socioambientais remete a uma intenção, motivadora de todo o trabalho, de ajudar as pessoas vulneráveis socioeconomicamente a ter vez e voz na agenda sistêmica (já que a imprensa acaba repercutindo os casos divulgados no Mapa e relatórios) e, formal (para que os políticos reconheçam as situações e ajam a partir das evidências trazidas nas publicações).

No caso específico da CPT, há forte presença de citações e considerações bíblicas, isto é, cristãs. A dimensão religiosa, traço peculiar da narrativa montada pela CPT, equivale de certo modo à dimensão da saúde imanente ao mapa da Fiocruz, a qual aponta para visão ampliada dos riscos à vida das populações em áreas de conflitos.

\section{ENCONTRO DAS ETIQUETAS E SEUS SENTIDOS GERAIS}

As etiquetas fazem com que a narrativa se abra em significações, oferecendo ao público mais elementos do que aqueles meramente causais. A constatação de que um discurso sobre conflitos é montado desta forma não é tão somente situacional, porque segundo as etiquetas dão a entender, o problema dos conflitos 
é estrutural e outras questões operam para legitimá-lo, em um contexto de apropriações de hegemonias de discursos, requerendo uma constante divulgação, crítica e, muitas vezes, denúncia.

A atualização da narrativa com novos dados nos sugere certa persistência dos conflitos, embora se deva questionar até que ponto esses dados são demandados pelas instâncias públicas às quais eles também se destinam. Não se pode afirmar que desconheçam a existência dos casos, mas é de se considerar que a elaboração de um argumento com tamanha atenção de duas sérias instituições no mínimo orientasse políticas públicas. Conforme nos mostram algumas situações, contraditoriamente as políticas públicas muitas vezes acabam sendo responsáveis pelos conflitos relatados.

Se por um lado, ao promover a ciência e ao falar da imprensa, a narrativa não dá muitas condições de as populações aparecerem - embora nos digam que implicitamente elas estão lá - não se pode deixar de constatar que as etiquetas escolhidas permitiram nos orientar claramente sobre quais são as implicações do problema e para quem.

Agrupadas, as etiquetas no final das contas demarcam o caráter político da narrativa. No "uso social” da ciência, na crítica à função do jornalismo (de atender, antes, o interesse público), na valorização da luta do homem do campo e da periferia (fora dos centros), na reflexão sobre o que os dados (não são somente números) representam e ao reunir diversos acontecimentos/fatos de nosso tempo, imediatamente descolados dos conflitos, temos a noção de que nenhuma situação é isolada, pontual e de que há vastos espaços por onde a narrativa escoaria.

A principal constatação que essas etiquetas possibilitam é, ademais, a de esclarecimento público do que sejam os conflitos socioambientais, suas causas, formas de mediação; diretrizes urgentes e em longo prazo de mudança. Porém, mesmo nas universidades, não se pode dizer que se entenda tal necessidade ou até se esses trabalhos de divulgação são conhecidos.

As etiquetas nos dizem que a Fiocruz e Pastoral desenvolvem um sistema próprio de interpretação da realidade. Prestam um serviço à sociedade que se sobrepõe às lacunas deixadas por outras instituições, incluindo os grandes veículos de comunicação, embora não os substituam. Se o Mapa de Conflitos e os Cadernos de Conflitos são potentes por conta do alcance a todo território nacional das ocorrências, limitam-se aos casos que seus agentes/colaboradores conseguiriam cobrir.

A forma como os materiais são estruturados mobilizam diferentes saberes, formas de conhecimento, principalmente quando constatamos as assinaturas dos textos que interpretam os dados e avaliam a cartografia dos conflitos. Se a luta parece ser por justiça socioambiental, obviamente o cenário que se instala ainda é de injustiça; de uma injustiça por terra e "hídrica". As etiquetas avançam também por servirem como diagnóstico de diversas comunidades. Até porque (não fica claro nas etiquetas, mas na leitura dos casos), há relação entre legislação, políticas públicas, doenças e empresas, por exemplo, relacionados aos conflitos.

Além disso, somos levados a pensar que se poderia fugir das controvérsias, revestindo o discurso sobre o fenômeno "de ciência". Mas isso produz quais efeitos à tentativa de dar vez e voz às pessoas? A ideia de que a visão da ciência muitas vezes não corresponde com a dos atores sociais nos ajuda a pensar que o uso da ciência, conforme nos mostram as etiquetas, é estratégico, segundo a CPT, por exemplo, em sua metodologia: "o rigor, os procedimentos metodológicos e o referencial teórico permitem sistematizar os dados de forma coerente e explícita; "alimentar e reforçar a luta dos próprios trabalhadores, em seu enfrentamento com o latifúndio" (CANUTO; COSTA; LUZ, 2015).

Os conflitos pertencem mais à sociedade do que às populações atingidas? Segundo as etiquetas, sim, à medida que possibilidades de solução e prevenção acabam sendo transferidas a outros atores/esferas. E ainda sobre a relação entre ciência e imprensa, quando os conflitos são divulgados, pelas etiquetas considera-se que a complexidade de ambos os campos não é inteiramente incorporada pela narrativa.

0 que a narrativa buscaria, então, seriam as suas credenciais. A da ciência, de outorgar autoridade/ 
legitimidade por meio de procedimentos e constatações empíricas e da imprensa, de ser capaz de alterar/influenciar a opinião pública. 0 que a ciência diz que é verdade, não se questionaria. 0 que a imprensa noticiaria, logo, seria também verdade (para o bem e para o mal).

Não há relação simétrica entre os fragmentos que justificariam a narrativa a partir dos Cadernos e Mapa de Conflitos. A forma como cada instituição trata ou sustenta essas etiquetas, discursivamente, não ocorre da mesma maneira. Até porque, como dissemos, a produção da CPT é mais vasta do que a da Fiocruz nesse sentido. A forma também como a CPT aponta para a dimensão religiosa não é apenas contundente, mas traço distintivo da realidade que constrói, enquanto que a relação entre conflito e saúde ambiental é um aspecto que a Fiocruz aborda prioritariamente.

À assimetria da narrativa poderíamos pensar, ocorreria justamente no fato de haver tantas vozes requerendo legitimar os fenômenos ao seu modo. Notavelmente, os saberes canônicos. Isso fica mais evidente quando ciência, religião e política aparecem acima dos vulneráveis ou em sua vanguarda, servindo de escudo. Esta posição da narrativa parece relegar aos atingidos uma posição passiva no sentido de que esperariam os efeitos benéficos após os casos serem divulgados.

Ao presumir também a evolução dos casos, a narrativa não apenas funciona como diagnóstico como antecipa o porvir dos conflitos. No fim, se ampara das contradições imanentes aos documentos que constroem a realidade: não são espelho. Ao optar por construir a sua noção de conflito, a narrativa nivela situações que estariam sujeitas a procedimentos outros de validação de lutas, como a imprensa faz, cobrindo quase sempre aquilo que tem maior apelo, baseada em valor notícia e critérios de noticiabilidade.

\section{REFERÊNCIAS}

AFONSO, J.B.G.; CANUTO, A.; LUZ, R.C.S.L. Conflitos no campo Brasil: 2003. Goiânia: CPT, 2004.
BRASIL. Ministério do Meio Ambiente. Conflitos: estratégias de enfrentamento e mediação. Série Educação Ambiental e Comunicação em Unidades de Conservação, v.4. Brasília: MMA, 2015.

CANUTO, A. et al. Conflitos no Campo Brasil: 2006. Goiânia: CPT, 2007.

CANUTO, A. et al. Conflitos no Campo Brasil: 2007. Goiânia: CPT, 2008.

CANUTO, A. et al. Conflitos no Campo Brasil: 2008 Goiânia: CPT, 2009.

CANUTO, A. et al. Conflitos no campo Brasil: 2009. Goiânia: CPT, 2010.

CANUTO, A.; COSTA, E.R.C.; LUZ, C.R.S. Conflitos no campo Brasil: 2014. Goiânia: CPT, 2015.

CANUTO, A.; LAZZARIN, F.; LUZ, C.R.S. Conflitos no campo Brasil: 2012. Goiânia: CPT, 2013.

CANUTO, A.; LAZZARIN, F.; LUZ, C.R.S. Conflitos no campo Brasil: 2013. Goiânia: CPT, 2014.

CANUTO, A.; LUZ, C.R.S.; ANDRADE, T.V.P. Conflitos no Campo Brasil: 2015. Goiânia: CPT, 2016.

CANUTO, A.; LUZ, C.R.S.; WICHINIESKI, I. Conflitos no campo Brasil: 2010. Goiânia: CPT, 2011.

CANUTO, A.; LUZ, C.R.S.; WICHINIESKI, I. Conflitos no campo Brasil: 2011. Goiânia: CPT, 2012.

CANUTO, A.; LUZ, R.C.S.L. Conflitos no campo

Brasil: 2002. Goiânia: CPT, 2003.

CANUTO, A.; LUZ, R.C.S.L. Conflitos no campo

Brasil: 2004. Goiânia: CPT, 2005.

CANUTO, A.; LUZ, R.C.S.L. Conflitos no campo

Brasil: 2005. Goiânia: CPT, 2006. 
FERREIRA, L.C. Conflitos sociais e uso dos recursos naturais: breves comentários sobre modelos teóricos e linhas de pesquisa. Política e Sociedade, n.7, 2005.

GALTUNG, J. Peace by Peaceful Means: Peace and Conflict, Development and Civilization. Sage Publications: Oslo. 1996. Disponível em: <https:// goo.gl/wsUT52 >. Acesso em: 19 mar. 2017. KELLER, A.C. Science in environmental policy. Massassuchets: The MIT Press, 2009.

LEROY, J.P.; PORTO, M.F.; PACHECO, T. (Org.)

Injustiça ambiental e saúde no Brasil: o mapa de conflitos. Rio de Janeiro: Fiocruz, 2013.
LEROY, J.P.; PORTO, M.F.; PACHECO, T. (Org.) Mapa de conflitos envolvendo injustiça ambiental e saúde no Brasil. Rio de Janeiro: Fiocruz, 2010.

Disponível em: <https://goo.gl/T5BT1d>. Acesso em: 19 mar. 2017.

VALENCIO, N.; ZHOURI, A. (Org). Formas de matar, de morrer e de resistir: limites da resolução negociada de conflitos ambientais. Belo Horizonte: FMG, 2013. 
Recebido em: 10 de Maio de 2017

Avaliado em: 2 de Junho de 2017

Aceito em : 2 de Junho de 2017
1. Programa de Pós-Graduação em Divulgação Científica e Cultural, Laboratório de Estudos Avançados em Jornalismo - Universidade Estadual de Campinas. Email: lessaedvan@gmail.com

2. Pós-Doutor no Goldsmiths College, University of London; Professor Livre Docente,Faculdade de Educação,Universidade Estadual de Campinas. Email: acamorim@unicamp.br 